\title{
Recent Developments in Pathogen Detection Arrays: Implications for Fungal Plant Pathogens and Use in Practice
}

\author{
Bart Lievens and Bart P. H. J. Thomma
}

First author: Centre of Microbial and Plant Genetics (CMPG), Katholieke Universiteit Leuven, Kasteelpark Arenberg 20, B-3001 HeverleeLeuven, Belgium and Scientia Terrae Research Institute, Fortsesteenweg 30A, B-2860 Sint-Katelijne-Waver, Belgium; and second author: Laboratory of Phytopathology, Wageningen University, Binnenhaven 5, 6709 PD Wageningen, The Netherlands. Accepted for publication 22 August 2005.

\begin{abstract}
Lievens, B., and Thomma, B. P. H. J. 2005. Recent developments in pathogen detection arrays: Implications for fungal plant pathogens and use in practice. Phytopathology 95:1374-1380.

The failure to adequately identify plant pathogens from culture-based morphological techniques has led to the development of culture-independent molecular approaches. Increasingly, diagnostic laboratories are pursuing fast routine methods that provide reliable identification, sensitive detection, and accurate quantification of plant pathogens. In addition, since plants or parts thereof can be infected by multiple pathogens, multiplex assays that can detect and quantify different pathogens simultaneously are highly desirable. Technologies that can meet these requirements, especially those involving polymerase chain reaction, are being
\end{abstract}

ABSTRACT developed and implemented in horticultural and agricultural practice. Currently, DNA array technology is the most suitable technique for multiplex detection of plant pathogens. Recently, a quantitative aspect was added to this technology, making DNA arrays highly attractive for various research and practical applications. Here, we review the most important recent advances in molecular plant pathogen diagnostics, with special attention to fungal molecular diagnostics. In addition to their applicability in practice, the different criteria that have to be fulfilled for developing robust detection procedures that can routinely be used by diagnostic laboratories are discussed.

Additional keywords: diagnosis, disease management, high-throughput, phytopathogen.
The lack of rapid, accurate, and reliable means by which plant pathogens can be adequately detected, identified, and quantified is one of the main limitations in plant disease management. Traditionally, the most predominant techniques used to identify plant pathogens relied upon culture-based morphological approaches. The major limitations of these methods, however, are the reliance on the ability of the organism to be cultured, the time consuming and laborious nature, and the requirement for extensive taxonomical knowledge, all together often complicating timely disease management decisions. Molecular techniques can circumvent many of these drawbacks, especially if they make use of the polymerase chain reaction (PCR) (34). In general, these methods are much faster, more specific, more sensitive, and more accurate, and can be performed and interpreted by personnel with no specialized taxonomical expertise. Perhaps even more important, these techniques allow detection of nonculturable microorganisms. However, whereas these methods are routinely used in the diagnosis of human diseases (50), they are not yet widely used for routine plant pathogen detection. One of the reasons is that, although generally most of these assays are reliable, they target only a single pathogen, making comprehensive screening of complex samples relatively unprofitable. Therefore, the major challenge currently is the development of multiplex pathogen detection assays that, in addition, allow quantification and are suitable for implementation in practice.

In this review, we discuss recent advances in PCR-based plant pathogen diagnostics, with special attention to fungal molecular diagnostics. In addition to their applicability in practice, the different requirements for developing robust detection procedures

Corresponding author: B. P. H. J. Thomma; E-mail address: bart.thomma@wur.nl

DOI: 10.1094/PHYTO-95-1374

(C) 2005 The American Phytopathological Society that can be routinely used by diagnostic laboratories are discussed. For a description of the typical features and some of the applications of these techniques, we refer to other recent reviews $(28,33)$.

\section{REQUIREMENTS FOR TECHNOLOGY IMPLEMENTATION IN PRACTICE}

Since its introduction in the mid-1980s, PCR has become a fundamental aspect of fungal molecular diagnostics, and several technologies based on PCR have been developed since then (28, 33). However, although extensively used as a tool in (academic) research, the use of PCR-based technologies in horticultural and agricultural practice is still limited $(33,48)$. Nevertheless, several areas would benefit from the commercial availability of such detection assays. With the opening of the borders of many countries and increased free-trade agreements, rapid testing for possible contamination with quarantine organisms is in high question. In addition, in order to be able to take timely control measures, the question from commercial growers for rapid, affordable pathogen detection assays is increasing. However, different requirements have to be met before new detection methods are implemented in practice. These requirements can be separated into technical and economical demands. Whereas the technical demands are absolutely required for the development of any successful diagnostic method, the economical criteria are important guidelines for the development of a commercially attractive assay.

Technical demands. When developing a tool for plant pathogen diagnostic purposes, several technical aspects related to plant disease management on one hand, and regulatory issues on the other hand, are to be considered. These aspects mainly concern specificity, sensitivity, and robustness. In addition, multiplexing and quantification are increasingly becoming required features for a diagnostic assay. 
Specificity. The ability to specifically detect the target pathogens is vital for all diagnostic applications. One of the most important advantages that molecular-based detection techniques have over conventional diagnostic methods is the power to, in principle, distinguish closely related organisms. For fungal molecular diagnostics, ubiquitously conserved genes are frequently used as target genes. Closely related microbial species often differ in a single (single-nucleotide polymorphism [SNP]) to a few bases in such genes. However, the high degree of specificity of nucleic acid-based detection techniques, achieved through the use of PCR primers, hybridization probes, or detector oligonucleotides, allows detecting such SNPs $(9,30,37)$. Since closely related pathogens might have a different host range or display a completely different pathogenicity, this is an extremely important trait. Ultimately, to enhance specificity of a diagnostic assay, a combination of multiple unique diagnostic regions can be exploited.

Obviously, the specificity of nucleic acid-based techniques is determined by the sequences that are targeted. In general, there are two approaches to select target sequences. The first, and most common, strategy involves targeting ubiquitously conserved known genes carrying sequence variation that can be exploited. Currently, the primary target in fungal molecular diagnostics is the nuclear ribosomal DNA (rDNA), which has been extensively used in molecular phylogenetic studies and is therefore well characterized (59). A large amount of rDNA sequence data is available in public databases, which aids the design of a diagnostic assay. These extensive sequence data allow comparison of sequences which permits, in turn, determining diagnostic regions harboring the required specificity. Apart from the discriminatory potential, the high copy number of rDNA genes in any genome permits a highly sensitive detection.

Fungal rDNA occurs as a structured unit consisting of three ribosomal RNA subunit genes that are separated by internal transcribed spacers (ITS). This ITS region is an area of particular importance to fungal diagnostics since it contains alternating areas of high conservation and high variability. This variability allows classification over a wide range of taxonomic levels (59), sometimes even below the species level (3). However, ribosomal sequences do not always reflect sufficient sequence variation to discriminate between particular species (54). Therefore, but also to corroborate discrimination based on ITS sequences, other housekeeping genes are becoming more intensively studied, including beta-tubulin (15), actin (58), and elongation factor 1-alpha (36).

The second strategy to select target sequences for detection of plant pathogens involves the screening of random parts of the genome to find diagnostic sequences. This can be achieved by several techniques, including random amplified polymorphic DNA (61) and amplified fragment length polymorphism (56) technology. Nevertheless, since the location of possible useful sequences in the genome is a priori unknown, there often are few sequence data available for comparison to other organisms in order to guarantee specificity. As a consequence, extensive screening is required to ensure specificity of the potential marker.

Sensitivity. Early detection of pathogens, e.g., before crops are infected or symptoms have developed, is essential to prevent diseases, spread of the inoculum, and economic losses. Therefore, diagnostic procedures should be highly sensitive.

Prior to the introduction of nucleic acid amplification methods, in particular PCR, nucleic acid-based diagnostics mainly involved the use of specific probes to report the presence of a certain organism (64). However, these methods often led to "false negatives" because of too low sensitivity. Because of this, PCR has been introduced in most molecular diagnostic assays in recent years, allowing detection of minute quantities of pathogen DNA. However, high sensitivity also causes one of the potential pitfalls of PCR technology: the slightest carry-over contamination can give rise to "false positive" results. Therefore, stringent conditions and controls are necessary, such as guarding the reagents and samples for accidental DNA contamination via aerosols, running negative controls simultaneously with the test samples, and having separate dedicated areas for pre- and post-PCR handling (22).

Recently, attempts are being made to assess the potential use of relatively novel highly sensitive amplification techniques such as rolling circle amplification (4) for pathogen detection. However, compared with PCR this procedure is fairly complicated (2) and relatively expensive. Therefore, it is important to realize what level of sensitivity is required for a method to be used for plant pathogen detection. Techniques more sensitive than conventional PCR amplification will probably not be required when assessing whether measures have to be taken to prevent yield losses, as the threshold level that has to be crossed can easily be detected using PCR. In contrast, sensitivity is very important for quarantine organisms for which a nil-tolerance is wanted.

Multiplexing. Most current molecular diagnostic assays used in plant pathology target one specific pathogen. However, because crops can be infected by numerous pathogens which are, in addition, often present in plants as complexes, it is desirable to develop assays that can detect multiple pathogens simultaneously. The first multiplex PCR-based strategies involved the use of multiple primer sets in the same reaction. Nevertheless, the development of a reliable multiplex PCR, in order to resolve at least a few amplicons by gel electrophoresis, is a significant technical challenge (13). For real-time PCR (17), the amplification process is monitored on-line, meaning that the size difference of amplicons to discriminate them on gels is not necessary. Nevertheless, in this case multiplexing is limited by the availability of dyes emitting fluorescence at different wavelengths on one hand, and the monochromatic character of the energizing light source in real-time PCR instruments on the other hand (31). As a result, detection of more than a few pathogens per assay is currently not possible using these strategies.

In contrast, array hybridization technology offers the possibility to add a multiplex aspect to PCR-based detection. In theory, DNA arrays, originally designed to study gene expression or to generate SNP profiles, can be used to detect an unlimited amount of different organisms in parallel $(24,28,32)$. The virtually unlimited screening capability of DNA arrays, coupled with PCR amplification, results in high levels of sensitivity, specificity, and throughput capacity (26). A pathogen detection array typically consists of many discretely located pathogen-specific detector sequences that are immobilized on a solid support, such as a nylon filter or a glass slide, to create a macroarray or a microarray, respectively. For signal amplification, in general the target DNA to be tested is amplified using consensus primers that target a genomic region containing the pathogen-specific sequences, and is labeled simultaneously or subsequently. In this way, it may thus be possible to differentiate a large number of organisms using a single PCR, provided that sufficient discriminatory potential exists within the region that is used. Subsequently, labeled amplicons are hybridized to the array under stringent conditions. In plant pathology, this approach was applied for identifying oomycete, nematode, bacterial, and fungal DNA from pure cultures $(14,25,26,55)$ as well as for the identification of a number of viruses (5). Despite these studies, for application in practice, identification of pathogens from pure cultures is not very relevant as, in the end, pathogens preferably should be assessed directly from plant and soil samples. In recent studies, the utility of this technology for the diagnosis of multiple pathogens in such environmental samples was shown $(26,29,35)$. Ultimately, such multiplex approach should lead to a comprehensive diagnostic kit that can detect all relevant pathogens of a specific crop. In an analogous manner, recently the first cross-pathogen group DNA array to detect human pathogens has been developed for high confidence identification of 11 bacterial species, five viruses, and two eukaryotic pathogens (62). 
Quantification. With respect to plant disease management, especially quantification of a pathogen upon its detection and identification is an important aspect as it can be used to estimate potential risks regarding disease development, spread of the inoculum, and economic losses. Apart from this potential, it provides the information required to take appropriate management decisions. However, the nonlinear nature of PCR amplification makes it challenging to relate the amount of amplicon produced in the reaction to the amount of target DNA initially present in the sample. Nevertheless, several studies have shown that by extensive optimization of PCR conditions, quantification in endpoint analysis-based PCR assays can be performed (20). More recently, the introduction of real-time PCR technology (17), which is characterized by on-line measurement of amplicons as they accumulate during each cycle, has improved and simplified methods for PCR-based quantification. Currently, in plant pathology, real-time PCR is the most reliable culture-independent technique to quantify the detected pathogen $(16,47)$ as well as for quantification of disease progress (7). However, to quantify more than a handful of plant pathogens in a single assay, real-time PCR instrumentation needs to be adapted or other techniques should be pursued.

As concluded in the previous paragraph, DNA array technology offers the most suitable technology for multiplex detection of plant pathogens. Therefore, implementation of a quantitative aspect to this technology would be highly desirable. Two recent studies have demonstrated that such a trait can be achieved (27, 44). Rudi et al. (44) developed a two-step PCR-based procedure, essentially to avoid bias in template-to-product ratio, followed by membrane-based array hybridization for multiplex detection and

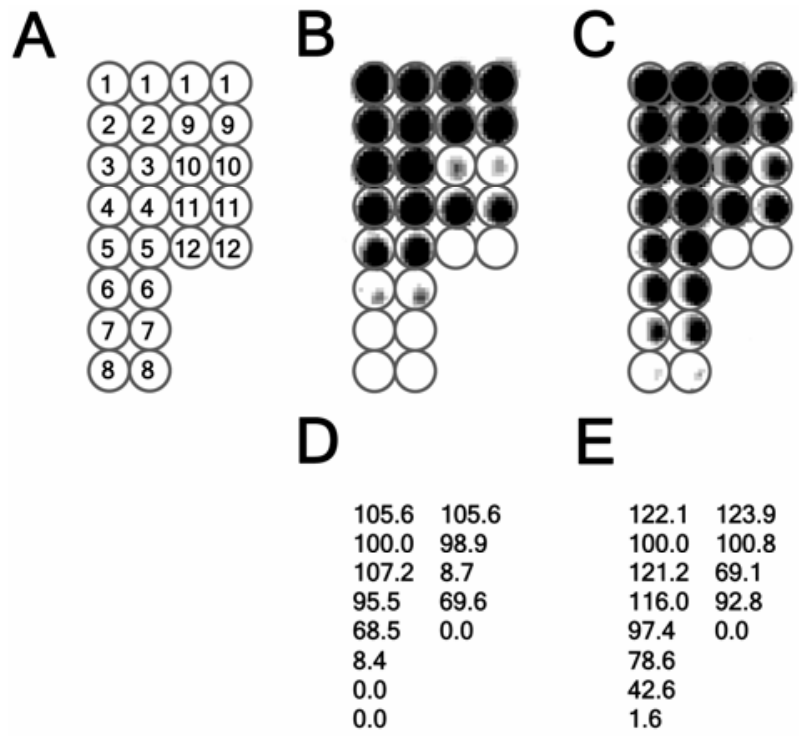

Fig. 1. Detection and quantification of fungal DNA utilizing a DNA macroarray. A, Scheme for the localization of the oligonucleotide detectors on the macroarray. B, Signals obtained upon hybridization of amplicons resulting from co-amplification of $50 \mathrm{pg}$ of Fusarium solani genomic DNA and $5 \mathrm{ng}$ of Verticillium albo-atrum genomic DNA. C, Signals obtained upon hybridization of amplicons resulting from co-amplification of $5 \mathrm{ng}$ of $F$. solani genomic DNA and $5 \mathrm{ng}$ of $V$. albo-atrum genomic DNA. D and E, Quantification of hybridization signals obtained in $\mathbf{B}$ and $\mathbf{C}$, respectively. Hybridization signal strength is reported relative to the average integrated optical density of a labeled reference control, marked 2 in panel $\mathbf{A}$. Values are means of two replicates. The target oligonucleotides (spotted at $8.0 \mathrm{fmol} / \mathrm{spot}$ ) to detect $F$. solani and $V$. albo-atrum are marked 10 and 11, respectively. In addition, several control oligonucleotides were spotted on the membrane, including a positive control for the hybridization [1], an oligonucleotide to target exogenously added control DNA [9], and a dilution series of a universal fungal detector oligonucleotide (absolute quantities are 8.0 [3], 2.0 [4], 0.5 [5], 0.2 [6], 0.1 [7], and 0.02 fmol [8]). The labeled reference oligonucleotide for detection and calibration [2] is also synthesized without label and spotted as a negative control [12]. quantification of DNA from genetically modified organisms. In the first few PCR cycles, targets are amplified with bipartite primers containing a universal $5^{\prime}$ tail region and a $3^{\prime}$ region specific to each target. After primer removal, a second PCR step is performed with a primer that hybridizes to the consensus sequences generated at both ends of the amplicons. Finally, specific oligonucleotides hybridizing to internal segments of the generated PCR products are sequence specifically labeled and hybridized to an array. Alternatively, Lievens et al. (27) showed that while accounting for specific criteria, pathogen DNA could be accurately quantified in concentration ranges typically encountered in horticultural practice by using a single PCR and macroarray hybridization (Fig. 1). These criteria include optimizing of PCR conditions, inclusion of the proper controls, and spotting the appropriate amounts of detector sequences. Whereas the first two were used to monitor potential bias in template-to-product ratio, the latter is important when it comes to accurate quantification of the hybridization signals.

Robustness. Obviously, each diagnostic assay developed should be robust, meaning that the methodology is highly reproducible. Therefore, the assay must be optimized and thoroughly tested against multiple targets and taxonomically related organisms, preferably isolated from various hosts or cultivars and from different geographical areas.

There are, however, specific obstacles that can affect the robustness and reliability of PCR-based diagnostic assays. PCR efficiency can be drastically reduced or even inhibited due to a variety of naturally occurring compounds that are co-extracted with the nucleic acids, such as phenolic compounds, humic acids, fulvic acids, and heavy metals. However, in many cases, these specific problems have been circumvented by improved extraction methods (33) or by the use of optimized extraction kits (27) by which highly purified DNA can be obtained from complex environmental samples. To improve reliability, PCR efficiency can be monitored by spiking the DNA extract with a certain amount of exogenous control DNA that can be amplified in the same reaction (10) or in parallel (27).

Validation. In many cases, detection procedures are developed to be used in specific research areas. As a consequence, these tools are generally only evaluated to work under the experimental conditions used. The steps required to evaluate new detection techniques for their direct use in practice are, however, rarely taken. New diagnostic procedures should be validated and standardized using worldwide ring tests before entering the market. Factors involved in validation include (i) specificity, (ii) sensitivity, (iii) reproducibility, (iv) accuracy of results, and (v) consistency and reliability of detection. The reliability of the test must be demonstrated unequivocally in blind tests in several different laboratories and results should be interpreted without any ambiguity. Preferably, the evaluation process must be monitored by an internationally recognized organization that ensures suitable expertise for the crop(s) and pathogen(s) involved in evaluating the test. As soon as new methods and reagents are validated, they can be officially recognized and recommended for plant pathogen detection and eventually replace more conventional gold standards in specific control directives $(32,52)$.

Economical demands. Apart from the technical criteria, several economical aspects have to be considered in the development of reliable detection methods that can be used by diagnostic laboratories. These demands include short diagnosis time and highthroughput capability. In addition, it should be possible to perform the test with a minimum of taxonomical expertise and at a minimum of cost. With regard to quarantine and export, legislation speed is the most important factor. When it comes to routine diagnosis requested by growers especially, cost is of high importance.

Speed. The speed at which results can be obtained is a very important issue for any commercial diagnostic tool, especially for the detection of pathogens of high-risk potential or when it comes 
to timely disease management decisions. Whereas culture-based traditional techniques are often laborious and time-consuming, and typically take days to weeks to complete, molecular detection techniques can generate accurate results much faster. In general, most molecular analyses can be accurately performed within 1 or 2 days, which is a considerable gain of time compared with the more conventional analyses.

High-throughput sample analysis. Another requirement for commercial applicability is the possibility to screen a large number of samples in a short period of time. Nowadays, when using molecular techniques, comprehensive screening of samples is made possible because of recent developments in automated highthroughput DNA extraction systems and because of the introduction of 96- to 384-well plate PCR systems. In addition, the development of DNA arrays for plant pathogen diagnosis has enabled screening of multiple pathogens in a single assay, eliminating the need of performing several singleplex assays. However, when many samples need to be processed using such multiplex assays in a short time, there is still a lack of high sample throughput capacity. Nevertheless, it can be expected that this will be achieved in the near future by the use of low-density arrays in a multiwell configuration, similar to the array systems that are currently being used for the pharmaceutical industry (12).

Expertise. Traditionally, the predominant techniques used to identify pathogens have relied upon morphological criteria and require highly specialized taxonomical expertise, which may take extensive education plus years of work in practice to acquire. However, since many pathogens are difficult to identify using morphological criteria, these techniques often lead to incomplete or even wrong diagnoses. Therefore, companies that provide diagnostic services are intensively searching for generic diagnostic tools that can be executed relatively easily and interpreted by technicians with a general education in molecular biology.

Cost issues. Cost is perhaps the most important consideration for routine pathogen testing since, relative to human clinical diagnostics, the willingness to spend money on expensive plant disease diagnosis is limited. This is caused by the fact that profit margins in agriculture and horticulture are often low as is the emotional value of a crop. On the other hand, when it comes to regulatory issues and risk management of exotic pathogens, other criteria like specificity, sensitivity, and speed are more important than cost.

While nucleic acid-based assays provide an excellent opportunity for rapid and precise detection, currently their success largely depends on well-equipped laboratory facilities. Therefore, first of all, companies that provide diagnostic services should compare the many advantages afforded by nucleic acid-based diagnostic assays to the cost of establishing and maintaining a suitable laboratory environment.

When large numbers of samples need to be assessed for the presence of one specific pathogen (as in some quarantine testing programs), diagnostic assays that can detect only single pathogens may be the most cost-effective. In contrast, when one has no idea about the causal agent of a disease or when several pathogens need to be targeted simultaneously, detection of multiple pathogens increases efficiency, reduces cost, and saves time. With regard to a grower, it is the price that one has to pay that counts. In general, a multiplex assay, like a DNA array-based test, is the most cost effective per sample because the use of a singleplex assay often requires multiple consecutive analyses to determine and confirm the cause of a disease, hence increasing the price per sample analyzed.

Nevertheless, the price of such DNA array-based analysis is largely determined by the instruments used. In general, there are two types of DNA arrays, membrane-based macroarrays and high-density microarrays using a glass slide (49) or beads (63). Whereas macroarray-based detection generally does not require specialized equipment, highly specialized instruments are needed for microarray fabrication and reading. As a consequence, implementation of microarray technology for disease diagnostic use in plant pathology is currently relatively expensive and therefore commercially unattractive. In addition, macroarrays are generally more sensitive than microarrays since spots on a macroarray often contain higher amounts of detector oligonucleotides (8), favoring the use of macroarrays. Besides, high density is probably not a necessity for host-based diagnostic assays since the number of major pathogens of a given crop is usually not more than 100 .

\section{POTENTIAL PITFALLS AND LIMITATIONS}

Molecular methods have become increasingly important to specifically detect pathogens and, as indicated above, different regions of the genome can be targeted to obtain the desired specificity. In recent years, multiplexing and quantification are being implemented as traits to several of these technologies. However, despite all their advantages, there remain limitations to molecular technologies that can hamper accurate pathogen detection and quantification. Nevertheless, most of these are inherent to the classical detection methods as well.

First, misclassification of strains is a regularly occurring phenomenon in fungal taxonomy. Historically, closely related fungi have been grouped into a single species and subsequently to a certain genus largely based on similarities in morphological and biological features (53). However, very poorly defined genera and genera containing asexual fungal species such as Fusarium and Rhizoctonia are known to often contain unrelated species $(23,41)$. As a result, relationships based on these morphological and biological traits are not always reflected by the phylogenies that are revealed using nucleic acid-based characterization techniques (53). Consequently, finding DNA sequences that are shared by all members of a given species or genus may be challenging. Therefore, efforts to solve misclassifications should be closely monitored. Presently, there is a trend to reconstruct phylogenies based on orthologous DNA sequences, known as "DNA barcodes" (18). However, controversy exists over the value of DNA barcoding, largely because species determinations based solely on the amount of genetic divergence in one gene could result in incorrect species recognition (60).

Another difficulty for molecular detection of certain plant pathogens is the existence of fungal species that contain pathogenic as well as nonpathogenic or even beneficial strains. This is a known phenomenon for complex species such as $F$. oxysporum, $F$. solani, and $R$. solani (40). Since these differences can very often not be resolved by targeting the known and generally used conserved genes, target sequences should preferably be derived from genes that are directly linked to pathogenicity $(21,40)$. As long as no molecular markers are available for these species complexes that allow for discrimination between pathogenic and nonpathogenic strains, pathogenicity tests with different hosts or cultivars need to be performed to determine whether or not a specific isolate is a pathogen of a specific crop.

In addition, the lack of adequate sequence information can hamper the development of a reliable molecular diagnostic assay. However, sequence data in public databases are continuously increasing which also allows validating current phylogenetic classifications. As a result, integration of more organisms into detection systems should become possible, and identification of emerging pathogens is likely to become an easier task. In this respect, the increasing availability of full-genome sequences of plant pathogens is a desirable development.

In consideration that PCR can also amplify DNA from dead or nonactive organisms, detection of nonviable propagules, and thus the risk of false positives, should be taken into account. This is particularly relevant for pathogens subjected to elimination treatments such as disinfection or antibiotics. Nevertheless, the rate of DNA degradation from dead cells in soils should be considered 
fairly high due to the high microbial activity, suggesting that interference by DNA derived from nonviable cells might be of less importance (19). The rate of DNA breakdown depends on soil type (42) and moisture content (6). Because DNA degradation occurs more slowly in dehydrated soils (6), reliable diagnosis, especially of samples from dry fields, may be perverted by detection of nonviable organisms. However, since persisting soil desiccation generally does not occur in horticultural or agricultural practice, this should not be of major concern. To exclude detection of nonviable organisms, PCR-based diagnostics may be combined with a pre-culturing step (46). Because only the viable propagules will grow, selection of living organisms is guaranteed. In addition, by this culturing step the detection limit is increased and potential PCR inhibiting compounds from the original sample are eliminated $(38,46)$. However, disadvantages to this approach are the labor-intensive and time-consuming nature, implications for quantification since the initial amount of target is influenced in an uncontrolled manner, and the inability to detect organisms that are either slow or difficult to grow or nonculturable. A perhaps more attractive alternative is the use of DNA-binding dyes such as ethidium monoazide (EMA) to distinguish viable from nonviable organisms (43). Since dead cells have compromised plasma membranes, EMA is able to selectively penetrate dead cells where it intercalates into DNA upon photoactivation. Once this takes place, EMA-bound DNA inhibits PCR amplification and thus allows the selective amplification of targets from living organisms. Another alternative is the use of RNA as a target instead of DNA, in combination with reverse transcriptase-PCR (RT-PCR). Since RNA is less stable than DNA, RNA will be degraded more quickly in dead organisms. In addition, messenger RNA (mRNA) is only produced by metabolically active cells, making mRNA suitable to selectively detect living microorganisms. However, because of the extreme sensitivity to degradation, specific precautions should be taken to isolate RNA from environmental samples.

As mentioned previously, rDNA sequences are currently the primary target for diagnostic development. Whereas the high copy number of this gene allows sensitive detection, this may, however, complicate pathogen quantification in environmental samples. More importantly, accurate quantification would be biased if it should appear that the copy number of the rDNA repeats significantly varies between different isolates of the same species. Nevertheless, to our knowledge, this has not been reported to date. Another factor that can hamper reliable quantification is the potential presence of both spores and mycelium, which are coextracted during DNA extraction (11). However, at present, it is still unclear how this proportion varies under horticultural conditions. In addition, because the majority of spores are likely to be found in the upper layers of a soil, they are less likely to be of concern when deeper soil samples are taken (11).

Other potential bottlenecks are sampling procedures and sampling size. As the amount of material necessary for analysis reduces with the development of more sensitive technologies, developing appropriate sampling strategies that account for possible spatial variability is becoming even more challenging than previously. The sampling plan should be performed in a manner that ensures a statistically representative sample. Nevertheless, Ranjard and coworkers (39) found that DNA extracted from multiple sampling aliquots of soil of $\geq 1 \mathrm{~g}$ had no effect on the assessment of fungal diversity, whereas variations were observed between replicates of smaller samples. Therefore, to minimize variation between different molecular analyses, a standard sample size should be used. Currently, pooling multiple small samples taken from a plant into one extraction or using subsamples taken from a homogenized soil sample may be the preferred sampling method. However, concentrating pathogen inoculum or DNA may be appropriate for certain pathogens, especially for those with limited distribution capabilities.
Finally, and very importantly, with respect to plant disease management, pathogen densities need to be coupled to thresholds at which damage may occur, and translated in accurate advice to growers. Therefore, extensive ecological studies need to be conducted, studying the behavior of a pathogen in relation to both biotic and abiotic factors of its environment.

\section{CONCLUSIONS AND FUTURE PROSPECTIVES}

Increasingly, diagnostic laboratories and inspection agencies are searching for fast routine methods that provide reliable identification, sensitive detection, and accurate quantification of potentially plant pathogenic organisms. In addition, multiplex detection is an important aspect, taking into account efficiency, cost, time, and labor. Currently, DNA array technology is the most suitable technique to detect multiple plant pathogens in a single assay. Recently, a quantitative aspect was added to a macroarraybased assay (27), making this technology highly attractive for its use in practice, and several diagnostic companies have implemented this technology to routinely detect plant pathogens in environmental samples. For instance, Microbiometrix (Belgium), Relab Den Haan (the Netherlands), and DNA Scan (Germany) are using a commercially available macroarray combined with ITS PCR for routine diagnosis of over 50 different plant pathogens including fungi and bacteria. In addition to diagnosis, the same approach is used by Blgg (Spain) as a pathogen monitoring tool in hydroponics to prevent diseases by regularly assaying water samples. Based on timely and regular analyses, preventive treatments can be properly described and performed, and in case infections are monitored the afflicted plants can be cured or removed. Whereas previously preventive treatments were frequently applied without the knowledge of actual pathogen populations, this approach should result in well-founded control measures. Ultimately, this concept should reduce the number of treatments and thus result in minimal environmental impacts.

Obviously, the future will bring new technologies for detecting plant pathogens, largely because of the current efforts in genomics and molecular biosystematics and because of new platforms that have been developed primarily in the field of clinical medicine or even in the field of biological warfare. Whenever appropriate, they generally find their way somewhat later to plant pathogen diagnostics as well. This can be illustrated by DNA array hybridization, essentially a reverse dot blot technique, which was originally developed to detect mutations related to different human genetic disorders (45) and was subsequently successfully applied to plant pathology $(14,25,26,35,55)$. Another example includes the development of affordable, portable realtime PCR instruments such as the SmartCycler (Cepheid, Inc., Sunnyvale, CA) that was originally designed for military personnel to rapidly detect biological threats in the field. Nowadays, it enables sensitive on-site diagnosis of specific pathogens (48).

Most progress can be expected from the development of simple and rapid devices for on-site pathogen detection such as lateral flow assays (51) or biosensors. In clinical diagnostics, biosensors that use DNA-based methods are currently being developed (57). These devices contain a biological recognition element (e.g., specific DNA sequences) coupled with a physical transducer that translates recognition (e.g., hybridization) into a measurable electronic signal such as light, current, or frequency. When applied to the diagnosis of plant pathogens, this should lead to the development of simple, rapid, on-site detection systems. Another interesting development in medical diagnostics is the lab-on-a-chip instrument which integrates several processes (from DNA extraction to DNA analysis) within a single, portable, and fully automated instrument $(1,57)$. However, it is unlikely that many of these devices will meet the desired requirements mentioned before in the near future. It is likely that only those technologies that are cost-effective will be used in plant pathogen diagnostics. 


\section{ACKNOWLEDGMENTS}

We thank the 'Vlaams Instituut voor de bevordering van het Wetenschappelijk-Technologisch Onderzoek-Vlaanderen' (IWT-010121; IWT040169) and De Ceuster Corp. (Sint-Katelijne-Waver, Belgium) for financial support of our work. B. P. H. J. Thomma was supported through a VENI grant of the Research Council for Earth and Life Sciences (ALW) with financial aid from the Netherlands Organization for Scientific Research (NWO).

\section{LITERATURE CITED}

1. Anderson, R. C., Su, X., Bogdan, G. J., and Fenton, J. 2000. A miniature integrated device for automated multistep genetic assays. Nucleic Acids Res. 28:e60.

2. Andras, S. C., Power, J. B., Cocking, E. C., and Davey, M. R. 2001. Strategies for signal amplification in nucleic acid detection. Mol. Biotechnol. 19:29-44.

3. Atkins, S. D., Hidalgo-Diaz, L., Clark, I. M., Morton, C. O., Montes De Oca, N., Gray, P. A., and Kerry, B. R. 2003. Approaches for monitoring the release of Pochonia chlamydosporia var. catenulata, a biological control agent of root-knot nematodes. Mycol. Res. 107:206-212.

4. Baner, J., Nilsson, M., Mendel-Hartvig, M., and Landegren, U. 1998. Signal amplification of padlock probes by rolling circle replication. Nucleic Acids Res. 26:5073-5078.

5. Boonham, N., Walsh, K., Smith, P., Madagan, K., Graham, I., and Barker, I. 2003. Detection of potato viruses using microarray technology: Towards a generic method for plant viral disease diagnosis. J. Virol. Methods 108:181-187.

6. Brim, H., Dijkmans, R., and Mergeay, M. 1994. Stability of plasmid DNA of Escherichia coli C600 and Alcaligenes eutrophus CH34 inoculated in desiccating soil. FEMS Microbiol. Ecol. 15:169-176.

7. Brouwer, M., Lievens, B., Van Hemelrijck, W., Van den Ackerveken, G., Cammue, B. P. A., and Thomma, B. P. H. J. 2003. Quantification of disease progression of several microbial pathogens on Arabidopsis thaliana using real-time fluorescence PCR. FEMS Microbiol. Lett. 228:241-248.

8. Cho, J.-C., and Tiedje, J. M. 2002. Quantitative detection of microbial genes by using DNA microarrays. Appl. Environ. Microbiol. 68:14251430.

9. Consolandi, C., Castiglioni, B., Bordoni, R., Busti, E., Battaglia, C., and De Bellis, G. 2001. Development of oligonucleotide arrays to detect mutations and polymorphisms. Minerva Biotechnol. 13:261-268.

10. Cubero, J., van der Wolf, J., van Beckhoven, J., and Lopez, M. M. 2002. An internal control for the diagnosis of crown gall by PCR. J. Microbiol. Methods 51:387-392.

11. Dickie, I. A., Xu, B., and Koide, R. T. 2002. Vertical niche differentiation of ectomycorrhizal hyphae in soil as shown by T-RFLP analysis. New Phytol. 156:527-535.

12. Eggers, M. D. 2000. High-throughput microarray technology. Innov. Pharm. Technol. 6:36-44.

13. Elnifro, E. M., Ashshi, A. M., Cooper, R. J., and Klapper, P. E. 2000. Multiplex PCR: Optimization and application in diagnostic virology. Clin. Microbiol. Rev. 13:559-570.

14. Fessehaie, A., De Boer, S. H., and Lévesque, C. A. 2003. An oligonucleotide array for the identification and differentiation of bacteria pathogenic on potato. Phytopathology 93:262-269.

15. Fraaije, B., Lovell, D. J., Rohel, E. A., and Hollomon, D. W. 1999. Rapid detection and diagnosis of Septoria tritici epidemics in wheat using a polymerase chain reaction/PicoGreen assay. J. Appl. Microbiol. 86:701708.

16. Gachon, C., Mingam, A., and Charrier, B. 2004. Real-time PCR: What relevance to plant studies? J. Exp. Bot. 55:1445-1454.

17. Heid, C. A., Stevens, J., Livak, K. J., and Williams, P. M. 1996. Real time quantitative PCR. Genome Res. 6:986-994.

18. Herbert, P. D. N., Cywinska, A., Ball, S. L., and deWaard, J. R. 2003. Biological identifications through DNA barcodes. Proc. R. Soc. London Ser. B 270:313-321.

19. Herdina, K., Neate, S., Jabaji-Hare, S., and Ophel-Keller, K. 2004. Persistence of DNA of Gaeumannomyces graminis var. tritici in soil as measured by a DNA-based assay. FEMS Microbiol. Ecol. 47:143-152.

20. Hu, X., Nazar, R. N., and Robb, J. 1993. Quantification of Verticillium biomass in wilt disease development. Physiol. Mol. Plant Pathol. 42:2336.

21. Johnson, R. D., Johnson, L., Kohomoto, K., Otani, H., Lane, C. R., and Kodama, M. 2000. A polymerase chain-reaction based method to specifically detect Alternaria alternata apple pathotype (A. mali), the causal agent of Alternaria blotch of apple. Phytopathology 90:973-976.

22. Kwok, S., and Higushi, R. 1989. Avoiding false positives with PCR. Nature 339:237-238.
23. Leslie, J. F., Zeller, K. A., and Summerell, B. A. 2001. Icebergs and species in populations of Fusarium. Physiol. Mol. Plant Pathol. 59:107-117.

24. Lévesque, C. A. 2001. Molecular methods for detection of plant pathogens-What is the future? Can. J. Plant Pathol. 24:333-336.

25. Lévesque, C. A., Harlton, C. E., and de Cock, A. W. A. M. 1998. Identification of some oomycetes by reverse dot blot hybridization. Phytopathology 88:213-222.

26. Lievens, B., Brouwer, M., Vanachter, A. C. R. C., Lévesque, C. A., Cammue, B. P. A., and Thomma, B. P. H. J. 2003. Design and development of a DNA array for rapid detection and identification of multiple tomato vascular wilt pathogens. FEMS Microbiol. Lett. 223:113-122.

27. Lievens, B., Brouwer, M., Vanachter, A. C. R. C., Lévesque, C. A., Cammue, B. P. A., and Thomma, B. P. H. J. 2005. Quantitative assessment of phytopathogenic fungi in various substrates using a DNA macroarray. Environ. Microbiol. doi: 10.1111/j.1462-2920.2005.00816.x.

28. Lievens, B., Grauwet, T. J. M. A., Cammue, B. P. A., and Thomma, B. P. H. J. 2005. Recent developments in diagnostics of plant pathogens: A review. Recent Res. Develop. Microbiol. 9:57-79.

29. Lievens, B., Hanssen, I. R. M., Vanachter, A. C. R. C., Cammue, B. P. A., and Thomma, B. P. H. J. 2004. Root and foot rot on tomato caused by Phytophthora infestans detected in Belgium. Plant Dis. 88:86.

30. Livak, K. J. 1999. Allelic discrimination using fluorogenic probes and the $5^{\prime}$ nuclease assay. Genet. Anal. 14:43-149.

31. Mackay, I. M., Arden, K. E., and Nitsche, A. 2002. Real-time PCR in virology. Nucleic Acids Res. 30:1292-1305.

32. Martin, R. R., James, D., and Lévesque, C. A. 2000. Impacts of molecular diagnostic technologies on plant disease management. Annu. Rev. Phytopathol. 38:207-239.

33. McCartney, H. A., Foster, S. J., Fraaije, B. A., and Ward, E. 2003. Molecular diagnostics for fungal plant pathogens. Pest Manag. Sci. 59:129142 .

34. Mullis, K. B., and Faloona, F. A. 1987. Specific synthesis of DNA in vitro via a polymerase-catalyzed chain reaction. Methods Enzymol. 155:335350.

35. Nicolaisen, M., Justesen, A. F., Thrane, U., Skouboe, P., and Holmstrom, K. 2005. An oligonucleotide microarray for the identification and differentiation of trichothecene producing and non-producing Fusarium species occurring on cereal grain. J. Microbiol. Methods 62:57-69.

36. O'Donnell, K., Kistler, H. C., Cigelnik, E., and Ploetz, R. C. 1998. Multiple evolutionary origins of the fungus causing Panama disease of banana: Concordant evidence from nuclear and mitochondrial gene genealogies. Proc. Natl. Acad. Sci. USA 95:2044-2049.

37. Papp, A. C., Pinsonneault, J. K., Cooke, G., and Sadee, W. 2003. Single nucleotide polymorphism genotyping using allele-specific PCR and fluorescence melting curves. BioTechniques 34:1068-1072.

38. Penyalver, R., Garcia, A., Ferrer, A., Bertolini, E., and Lopez, M. M. 2000. Detection of Pseudomonas savastanoi pv. savastanoi in olive plants by enrichment and PCR. Appl. Environ. Microbiol. 66:2673-2677.

39. Ranjard, L., Lejon, D. P. H., Mougel, C., Schehrer, L., Merdinoglu, D., and Chaussod, R. 2003. Sampling strategies in molecular microbial ecology: Influence of soil sample size on DNA fingerprinting analysis of fungal and bacterial communities. Environ. Microbiol. 5:1111-1120.

40. Recorbet, G., Steinberg, C., Olivain, C., Edel, V., Trouvelot, S., DumasGaudot, E., Gianinazzi, S., and Alabouvette, C. 2003. Wanted: Pathogenesis-related marker molecules for Fusarium oxysporum. New Phytol. 159:73-92.

41. Roberts, P. 1999. Rhizoctonia-Forming Fungi. A Taxonomic Guide. Royal Botanic Gardens, Kew, UK.

42. Romanowski, G., Lorenz, M. G., Sayler, G., and Wackernagel, W. 1992. Persistence of free plasmid DNA in soil monitored by various methods, including a transformation assay. Appl. Environ. Microbiol. 58:30123019.

43. Rudi, K., Moen, B., Dromtorp, S. M., and Holck, A. L. 2005. Use of ethidium monoazide and PCR in combination for quantification of viable and dead cells in complex samples. Appl. Environ. Microbiol. 71:10181024.

44. Rudi, K., Rud, I., and Holck, A. 2003. A novel multiplex quantitative DNA array based PCR (MQDA-PCR) for quantification of transgenic maize in food and feed. Nucleic Acids Res. 31:e62.

45. Saiki, R. K., Walsh, P. S., Levenson, C. H., and Erlich, H. A. 1989. Genetic analysis of amplified DNA with immobilized sequence-specific oligonucleotide probes. Proc. Natl. Acad. Sci. USA 86:6230-6234.

46. Schaad, N. W., Cheong, S., Tamaki, S., Hatziloukas, E., and Panopoulas, N. J. 1995. A combined biological amplification (BIO-PCR) technique to detect Pseudomonas syringae pv. phaseolicola in bean seed extracts. Phytopathology 85:243-248.

47. Schaad, N. W., and Frederick, R. D. 2002. Real-time PCR and its application for rapid plant disease diagnostics. Can. J. Plant Pathol. 24:250-258.

48. Schaad, N. W., Frederick, R. D., Shaw, J., Schneider, W. L., Hickson, R., Petrillo, M. D., and Luster, D. G. 2003. Advances in molecular-based 
diagnostics in meeting crop biosecurity and phytosanitary issues. Annu. Rev. Phytopathol. 41:305-324.

49. Schena, M., Shalon, D., Heller, R., Chai, A., Brown, P. O., and Davis, R. W. 1996. Parallel human genome analysis: Microarray-based expression monitoring of 1000 genes. Proc. Natl. Acad. Sci. USA 93:10614-10619.

50. Sebire, K., McGavin, K., Land, S., Middleton, T., and Birch, C. 1998. Stability of human immunodeficiency virus RNA in blood specimens as measured by a commercial PCR-based assay. J. Clin. Microbiol. 36:493498.

51. Smits, H. L., Eapen, C. K., Sugathan, S., Kuriakose, M., Gasem, M. H., Yersin, C., Sasaki, D., Pujianto, B., Vestering, M., Abdoel, T. H., and Gussenhoven, G. C. 2001. Lateral-flow assay for rapid serodiagnosis of human leptospirosis. Clin. Diagn. Lab. Immunol. 8:166-169.

52. Stead, D. E. 1999. Validation of diagnostic methods for diseases such as potato ring rot and potato brown rot for use within the European Union. Page 68 in: Program Book, APS/CPS Joint Meeting. The American Phytopathological Society, St. Paul, MN.

53. Taylor, J. W., Jacobson, D. J., Kroken, S., Kasuga, T., Geiser, D. M., Hibbett, D. S., and Fisher, M. C. 2000. Phylogenetic species recognition and species concepts in fungi. Fungal Genet. Biol. 31:21-32.

54. Tooley, P. W., Carras, M. M., and Falkenstein, K. F. 1996. Relationships among group IV Phytophthora species inferred by restriction analysis of the ITS2 region. J. Phytopathol. 144:363-369.

55. Uehara, T., Kushida, A., and Momota, Y. 1999. Rapid and sensitive identification of Pratylenchus spp. using reverse dot blot hybridization. Nematology 1:549-555.

56. Vos, P., Hogers, R., Bleeker, M., Reijans, M., van de Lee, T., Hornes, M., Frijters, A., Pot, J., Peleman, J., Kuiper, M., and Zabeau, M. 1995.
AFLP: A new technique for DNA fingerprinting. Nucleic Acids Res. 23:4407-4414

57. Wang, J. 2000. From DNA biosensors to gene chips. Nucleic Acids Res. 16:3011-3016

58. Weiland, J. J., and Sundsbak, J. L. 2000. Differentiation and detection of sugar beet fungal pathogens using PCR amplification of actin coding sequences and the ITS region of the rRNA gene. Plant Dis. 84:475-482.

59. White, T. J., Bruns, T., Lee, S., and Taylor, J. 1990. Amplification and direct sequencing of fungal ribosomal RNA genes for phylogenetics. Pages 315-322 in: PCR Protocols: A Guide to Methods and Applications. M. A. Innis, D. H. Gelfand, J. J. Sninsky, and T. J. White, eds. Academic Press, San Diego, CA.

60. Will, K. W., and Rubinoff, D. 2004. Myth of the molecule: DNA barcodes for species cannot replace morphology for identification and classification. Cladistics 20:47-55.

61. Williams, J. G., Kubelik, A. R., Livak, K. J., Rafalski, J. A., and Tingey, S. V. 1990. DNA polymorphisms amplified by arbitrary primers are useful as genetic markers. Nucleic Acids Res. 18:6531-6535.

62. Wilson, W. J., Strout, C. L., DeSantis, T. Z., Stilwell, J. L., Carrano, A. V., and Andersen, G. L. 2002. Sequence-specific identification of 18 pathogenic microorganisms using microarray technology. Mol. Cell. Probes 16:119-127.

63. Yang, L., Tran, D. K., and Wang, X. 1998. BADGE, beads array for the detection of gene expression, a high-throughput diagnostic bioassay. Genome Res. 11:1888-1898.

64. Yao, C.-L., Magill, C. W., Frederiksen, R. A., Bonde, M. R., Wang, Y., and Wu, P.-S. 1991. Detection and identification of Peronosclerospora sacchari in maize by DNA hybridization. Phytopathology 81:901-905. 